\title{
Penerapan Metode Levenshtein Distance Dalam Mendeteksi Hasil Jawaban Peserta Kelas Daring Dengan Teknik Web Scraping Manual
}

\author{
Guntur Syahputra*, Ahmad Fitri Boy**, Nurcahyo Budi Nugroho** \\ * Program Studi Teknologi Rekayasa Multimedia, Politeknik Negeri Lhokseumawe \\ ** Program Studi Sistem Informasi, STMIK Triguna Dharma
}

\begin{tabular}{l}
\hline Article Info \\
\hline Article history: \\
Received Jul $12^{\text {th }}, 2020$ \\
Revised Aug $20^{\text {th }}, 2020$ \\
Accepted Oct $26^{\text {th }}, 2020$ \\
\hline Keyword: \\
First keyword \\
Second keyword \\
Third keyword \\
Fourth keyword \\
Fifth keyword
\end{tabular}

\begin{abstract}
Pandemi COVID 19 saat ini menyebabkan kegiatan belajar mengajar harus merubah sistem tatap muka untuk beralih kepada sistem daring, hal ini bukan menjadi alasan bagi pengampu atau penanggung jawab kelas menurunkan kualitas pengajaran. Evaluasi tetap harus dilakukan melalui pertanyaan dan tugas, namun karena dilakukan secara daring banyak peserta didik yang menjawab dengan tidak serius, menyalin dari laman web ataupun menyalin jawaban teman tanpa merubah data sedikitpun yang berasal sumber salinan. Levenshtein Distance adalah metode yang digunakan untuk medeteksi kemiripan data berbasis karakter (String Metric). Metode ini dapat membantu dan memudahkan pekerjaan pengajar dalam kelas daring untuk deteksi jawaban peserta, kemiripan jawaban yang mencapai 95\% dapat dideteksi dan diasumsikan sebagai jawaban hasil salinan. Sehingga dapat diambil tindakan terhadap peserta yang melakukan hal tersebut.
\end{abstract}

Corresponding Author:*First Author

Nama :

Program Studi

Sistem Informasi STMIK Triguna Dharma

Email: gunturcapt@yahoo.co.id

\section{PENDAHULUAN}

Pembelajaran Daring merupakan suatu tantangan yang harus dilaksanakan bagi tenaga pendidik di masa pandemi Covid 19. Hal ini merupakan sudah ditetapkan oleh peraturan KEMDIKBUD DIKTI sesuai Surat Edarannya Nomor 4 tahun 2020 tentang pelaksanaan pendidikan dalam masa darurat Covid 19 serta Surat Edaran Nomor 15 tahun 2020.

Meskipun dalam proses belajar dilakukan secara Daring para Pendidik dituntut tetap menjaga kualitas pendidikan sebagai mana mestinya sehingga Pendidik harus kreatif dan inovatif dengan menyediakan konten-konten yang menarik dan mempergunakan media yang mudah untuk di jangkau Peserta didik. Evaluasi merupakan salah satu cara untuk meningkatkan kualitas pendidikan [1], namun karena dilakukan secara daring evaluasi sering tidak efektif karena banyak peserta didik yang menjawab dengan tidak serius, menyalin dari laman web ataupun menyalin jawaban teman tanpa merubah data sedikitpun yang berasal sumber salinan. Sementara bagi pendidik untuk memeriksa dan membandingkan satu persatu jawaban perserta didik merupakan hal yang rumit membutuhkan waktu yang cukup lama. Untuk itu perlu adanya metode yang tepat sehingga siswa yang memiliki jawaban yang sama dapat dideteksi tingkat kemiripannya dan diketahui serupa dengan jawaban Peserta lain yang menjadi rujukan jawaban.

Untuk memeriksa jawaban peserta didik pada kelas daring perlu menentukan teknik web scraping/web scaning yang tepat agar proses dapat berlangsung secara efektif dan efisien, dalam penelitian ini digunakan web scraping manual dengan melihat satu persatu jawaban dan memindahkan jawaban tersebut kedalam aplikasi spreadsheet untuk selanjutnya akan diperiksa tingkat kemiripan antara satu dengan jawaban yang lain dengan metode Levenshtein Distance. Teknik web scraping manual dinilai efektif karena memiliki tingkat keakuratan tinggi dibandingkan dengan teknik web scraping lain. 
Levenshtein Distance adalah metode yang digunakan untuk medeteksi kemiripan data berbasis karakter (String Metric) dengan cara mengukur perbedaan jarak (Distance) antara 2 String [2]. Ditemukan oleh Vladmird Levensthein pada saat meneliti tentang kemampuan Koreksi kode biner dengan teknik Deletions, Insertions dan Revesals pada tahun 1965 [3]. Metode ini juga sudah banyak digunakan seperti pada penelitian yang mendeteksi identitas peserta ujian TryOut Bimbel Expert [4] dan banyak lagi penelitian yang berkaitan dengan deteksi kemiripan data.

\section{METODE PENELITIAN}

Penelitian ini dilakukan pada awal bulan mei 2020 sampai Juli 2020 (Sekitar 3 bulan) dengan melakukan obeservasi pada situs google classroom sebagai salah satu sarana kelas daring. Linear Squential Model mejadi pilihan untuk metode pengembangan sistem dengan fase-fase seperti pada gambar dibawah.

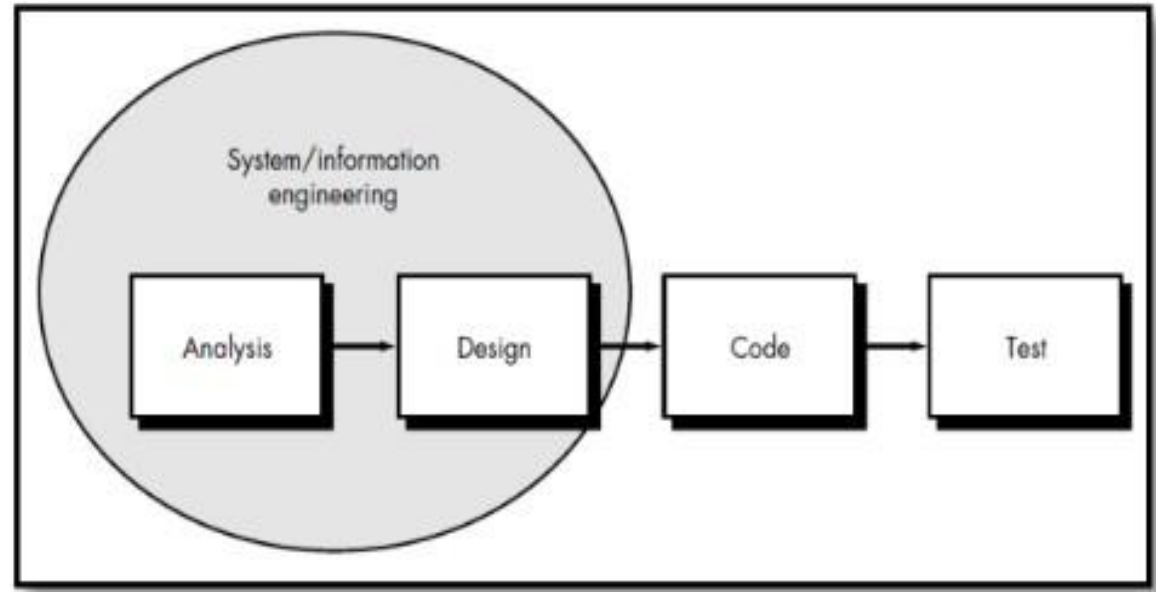

Gambar 1. Fase Metode Linear Squential Search

\section{Analisis}

Berdasarkan observasi yang telah dilakukan maka dapat digambarkan proses yang terjadi untuk mendeteksi kemiripan jawaban peserta didik pada kelas daring adalah: 1) Lakukan Web Scraping seluruh jawaban peserta, 2) Masukkan hasil scraping kedalam spreadsheet yang telah ditentukan formatnya, 3) Bandingkan setiap jawaban dengan masing-masing jawaban lain dengan metode Levensthein Distance, 4) Validasi persentase tingkat kemiripan yang telah disepakati dalam penelitian ini 95\%, 5) Tampilkan jawaban yang mirip.

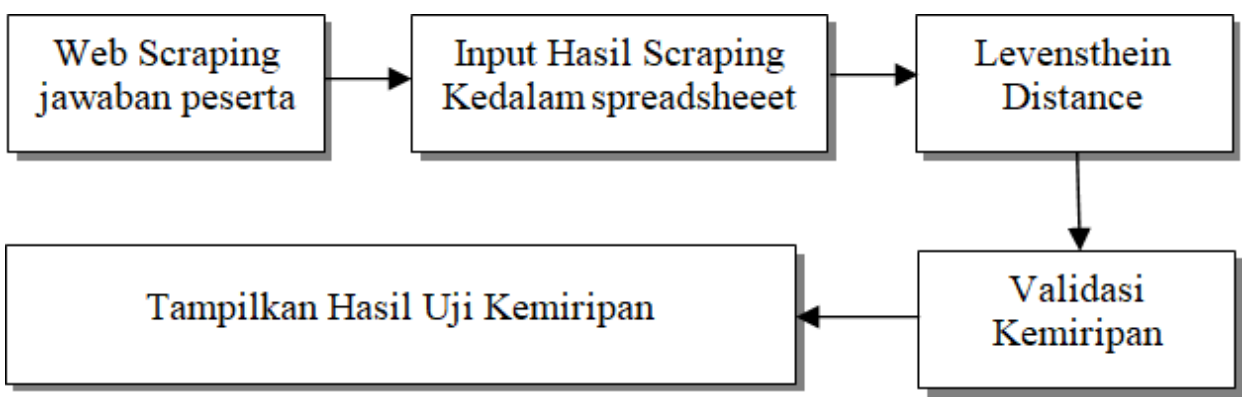

Gambar 2. Proses Deteksi Kemiripan 


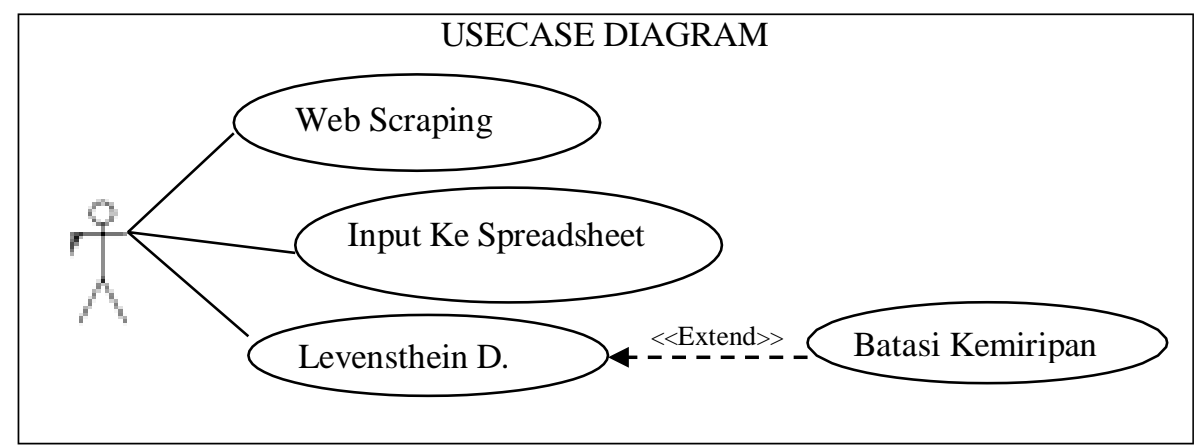

Gambar 3. Usecase Diagram

\section{Design}

Untuk memudahkan proses web scraping maka data yang diambil diletakan terlebih dahulu kedalam spreadsheet dengan format yang telah ditentukan dan untuk selanjutnya sekaligus di upload kedalam sistem pendeteksi kemiripan jawaban, berikut format spreadsheet:

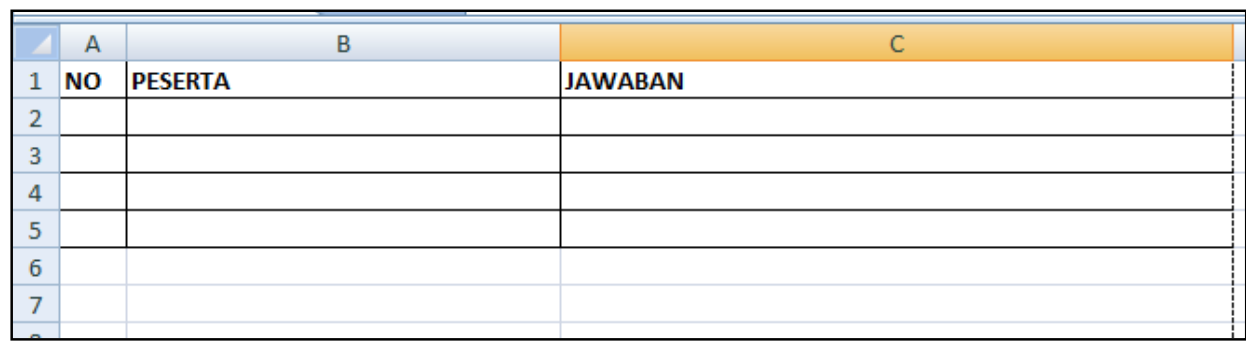

Gambar 4. Format Spreadsheet

Setelah dibentuk format spreadsheet maka untuk merancang aplikasi akan dimulai dengan membentuk database yang diperlukan, berikut rancangan database yang dipakai dalam aplikasi deteksi kemiripan jawaban peserta kelas daring.

Tabel 1. Data Jawaban

\begin{tabular}{|l|l|l|l|}
\hline No & Nama Field & Type Data & Keterangan \\
\hline 1 & id & Int & Primary key data peserta \\
\hline 2 & peserta & Varchar & Nama peserta \\
\hline 3 & jawaban & Memo & Jawaban peserta \\
\hline 4 & kemiripan & Varchar & $\begin{array}{l}\text { Persentasi kemiripan dengan } \\
\text { peserta lain }\end{array}$ \\
\hline
\end{tabular}

\section{Coding}

Metode levensthein distance mendekteksi kemiripan berdasarkan operasi-operasi perubahan sebuah string untuk menjadi sebuah string lain dalam sebuah string metric. Operasi perubahan yang dipakai teridiri atas insertion, deletion dan substitution [4]. Untuk setiap operasi yang digunakan maka akan menambahkan nilai jarak (Distance) perbedaan antara string yang dibandingkan, contoh:

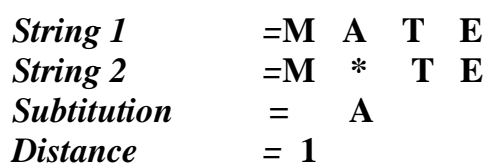




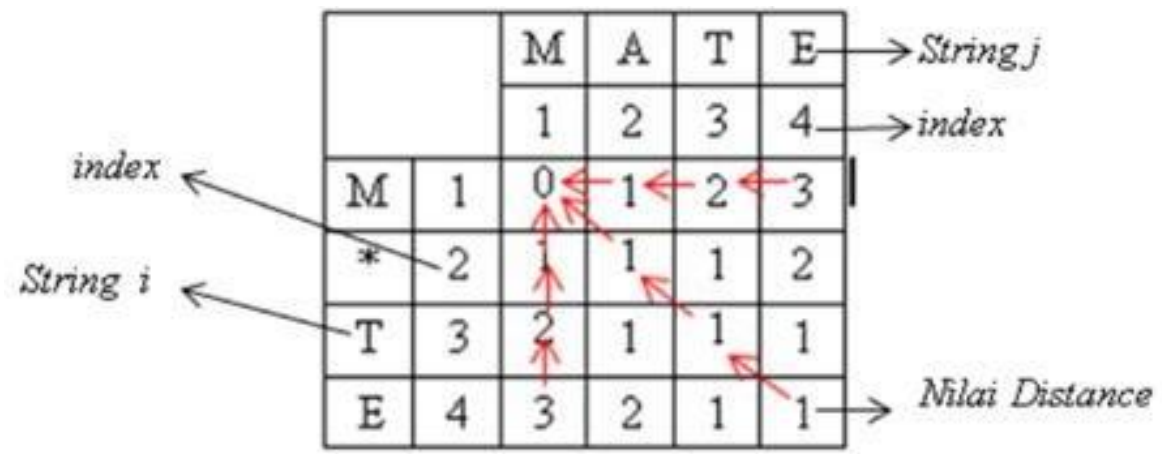

Gambar 5.Menghitung Distance

Setelah jarak distance ditemukan maka tingkat kemiripan (bobot similarity) akan dinyatakan dengan persentase, rumus yang digunakan adalah sebagai berikut:

$$
\text { Bobot Similarity }=\left(1-\frac{d[m, n]}{\operatorname{Max}(S, T)}\right) * 100 \% \quad \text { (1) }
$$

Dalam bahasa program PHP nilai distance dapat dikerjakan dengan sangat mudah, karena sudah disediakan function untuk pengujian maximal 255 karakter dalam satu perintah yaitu levenshtein(string1, string2). Berikut cuplikan pemrograman hitung distance dari metode levenshtein.

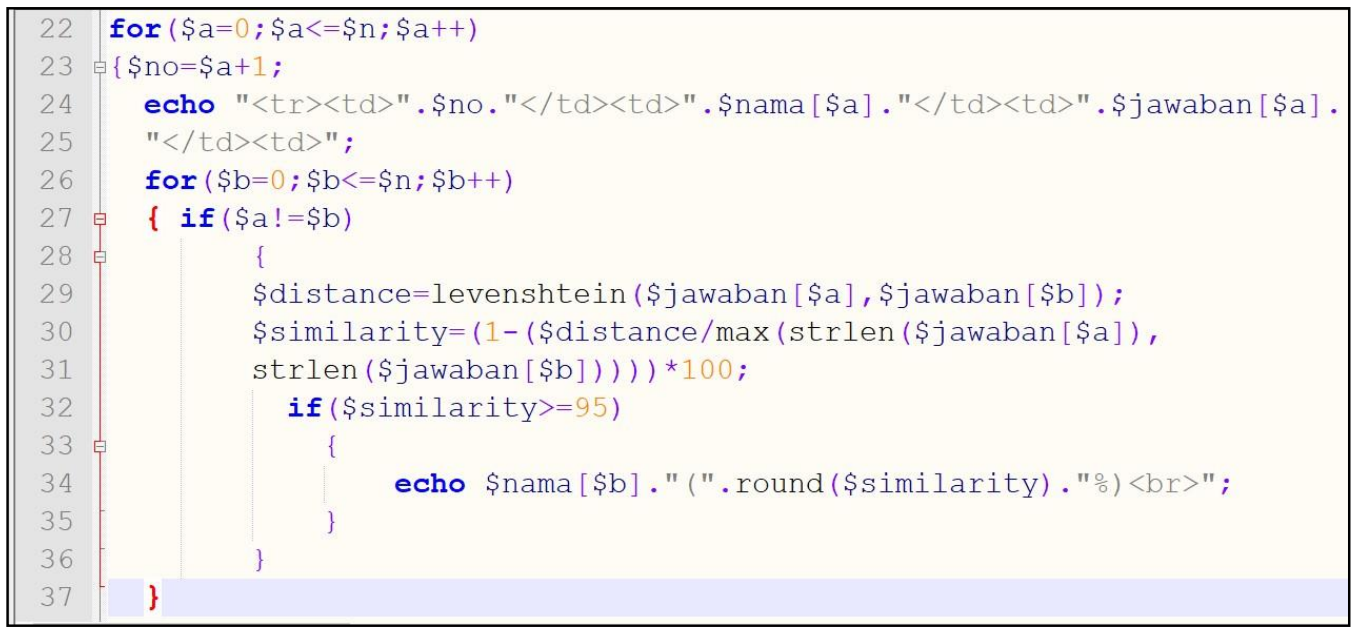

Gambar 6. Bagian Program

\section{Testing}

Untuk menguji hasil program maka dipilih sebuah media kelas daring yaitu Google Classroom dan diambil sebuah latihan seperti yang ditunjukan dalam gambar 7.

(4) Latihan 2

Guntur Syahputra 19 Jun

100 poin

Buatlah koding untuk menciptakan variable array sesuai dengan ide masing masing

Contoh

umur $=25,23,22,20,18$

Gambar 7. Soal latihan pada Google Classroom 
Dari contoh soal latihan diatas maka dapat dilakukan web scraping dan menyimpan dalam spreadsheet dalam penelitian digunakan Microsoft Excel, seperti pada gambar 8.

\begin{tabular}{|c|c|c|c|}
\hline 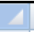 & A & B & $\mathrm{C}$ \\
\hline 1 & NO & PESERTA & JAWABAN \\
\hline 2 & 1 & Cris Samuel & $\begin{array}{l}\text { \#include }<\text { iostream }>\text { using namespace std; int main } 0 \text { \{ string jabatan[3]=\{'Karyawan','Staff,',Manager' }\} \text {; int } \\
\text { bonus[3] }\{500,600,700\} ; \text { cout }<<\text { jabatan[1]<<endl://tampil Staff cout }<<\text { bonus[2];//tampil } 700 \text { return } 0 ;\}\end{array}$ \\
\hline 3 & 2 & Cindy Emeliasna & $\begin{array}{l}\text { \#include }<\text { iostream }>\text { using namespace std; int main } 0\{\text { int umur }[7] \text {; umur }[0]=15 \text {; umur }[1]=18 \text {; umur }[2]=21 \text {; } \\
\text { umur }[3]=24 \text {; umur }[4]=27 \text {; cout }<<\text { 'Nilai pada array umur elemen ke ' }<<1<<\text { adalah }:<<\text { umur }[1]<<\text { endl; } \\
\text { cout }<<\text { 'Nilai pada array umur elemen ke ' }<<3<<\text { adalah }: '<<\text { umur }[3]<<\text { endl; return } 0 ;\}\end{array}$ \\
\hline 4 & 3 & fransisco Sitepu & 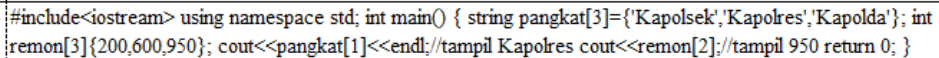 \\
\hline 5 & 4 & Imanuel Tarigan & 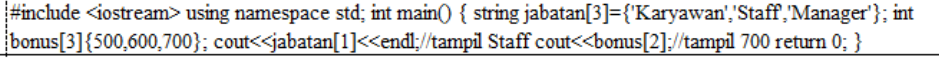 \\
\hline 6 & 5 & Meygel Christin & $\begin{array}{l}\text { \#include }<\text { iostream }>\text { using namespace std; int main } 0\{\text { int umur }[5]=\{25,23,22,20,18\} \text {; cout }<<\text { umur: ' }<< \\
\text { umur }[4]<<\text { endl; }\}\end{array}$ \\
\hline 7 & & & \\
\hline
\end{tabular}

Gambar 8. Hasil Web Scraping

Setelah Web Scraping di lakukan maka selanjut pengujian kemiripan dilakukan melalui aplikasi yang sudah dibuat untuk menerapkan Algoritma Levenshtein Distance, dan hasilnya dapat dilihat dibawah ini.

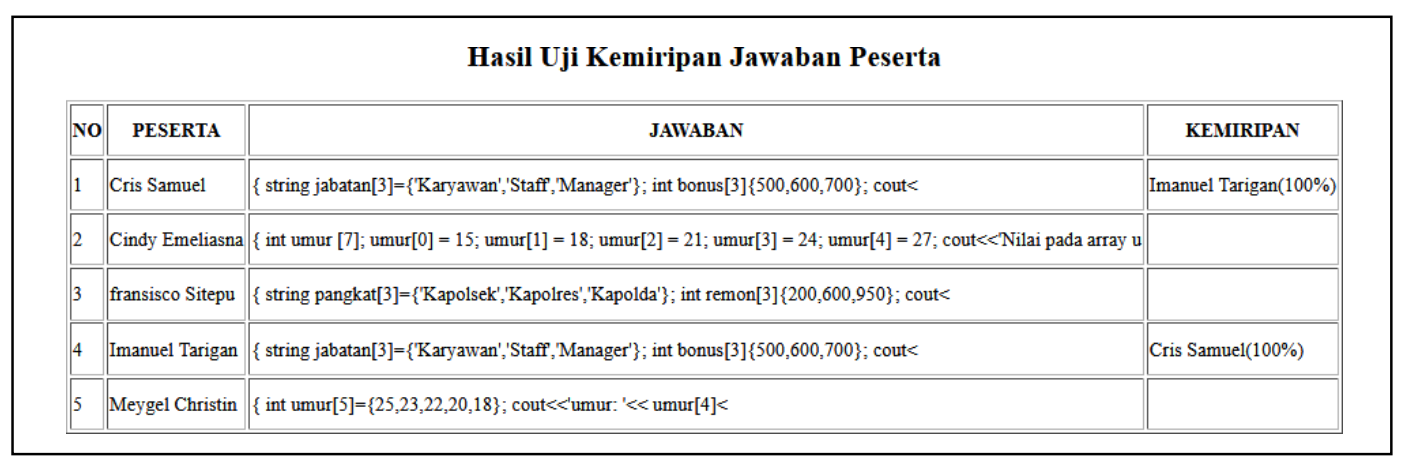

Gambar 9. Hasil Deteksi Kemiripan Jawaban

Pada pengujian diatas kemiripan hanya dimunculkan apabila bobot similarity-nya lebih besar dari $95 \%$ sehingga dapat disimpulkan jawaban tersebut memang merupakan jawaban yang dikerjakan dengan cara menyalin bukan dikerjakan secara mandiri, dan hasilnya dari 5 orang yang dijadikan sampel ditemukan 2 orang memiliki jawaban yang sangat mirip mencapai $100 \%$. Setelah diperiksa pada jawaban siswa pada classroom ternyata jawabannya sama persis dapat dilihat pada gambar dibawah ini.

\begin{tabular}{|c|c|}
\hline chris samuel 19 Jun & Imanuel Tarigan 19 Jun \\
\hline $\begin{array}{l}\text { \#include <iostream> } \\
\text { using namespace std; }\end{array}$ & $\begin{array}{l}\text { \#include <iostream> } \\
\text { using namespace std; }\end{array}$ \\
\hline $\begin{array}{l}\text { int main }() \\
\{ \\
\text { string jabatan[3]=\{"Karyawan", "Staff","Manager" }\} \text {; } \\
\text { int bonus }[3]=\{500,600,700\} \text {; }\end{array}$ & $\begin{array}{l}\text { int main }() \\
\{ \\
\text { string jabatan[3]=\{"Karyawan",'Staff",'Manager" }\} \text {; } \\
\text { int bonus }[3]\{500,600,700\} \text {; }\end{array}$ \\
\hline $\begin{array}{l}\text { cout }<<\text { jabatan[1] }<<\text { endl; } / / \text { tampil Staff } \\
\text { cout }<<\text { bonus[2];//tampil } 700 \\
\text { return } 0 \text {; } \\
\text { \} }\end{array}$ & $\begin{array}{l}\text { cout }<<\text { jabatan[1] }<<\text { endi;//tampil Staff } \\
\text { cout }<<\text { bonus[2];//tampil } 700 \\
\text { return } 0 \text {; } \\
\text { \} }\end{array}$ \\
\hline
\end{tabular}

Gambar 10. Jawaban Peserta 


\section{KESIMPULAN}

Penerapan Algoritma Levenshtein Distance sudah teruji untuk mendeteksi kemiripan data berupa string yang dapat dilihat pada penelitian-penelitian sebelumnya dan dalam penelitian ini algoritma Levenshtein Disntance juga sudah berhasil mendeteksi kemiripan jawaban peserta kelas daring. Harapan untuk perkembangan kedepanya agar deteksi jawaban bisa berlangsung dengan cepat, dengan menggunakan metode web scraping otomatis yang juga memperhatikan keakuratan hasil.

\section{UCAPAN TERIMA KASIH}

Penulis menyadari tidak akan berhasil bila tidak didukung oleh orang-orang yang terlibat didalamya untuk itu ucapan terima kasih yang sebesar-besarnya disampaikan kepada peneliti-peneliti sebelumnya yang menjadi dasar teoris yang mendukung penelitian ini, peserta kelas daring sebagai sampel penelitian kelas 2mia1 Tahun Ajaran Genap 2019/2020 di Kampus STMIK Trigna Dharma, serta seluruh yang terlibat langsung maupun tidak langsung.

\section{REFERENSI}

[1] B. Mahirah, "Evaluasi Belajar Peserta Didik (Siswa)," Idaarah J. Manaj. Pendidik., vol. 1, no. 2, pp. 257-267, 2017, doi: 10.24252/idaarah.v1i2.4269.

[2] B. P. Pratama and S. A. Pamungkas, "Analisis Kinerja Algoritma Levenshtein Distance dalam Mendeteksi Kemiripan Dokumen Teks,"J. “LOG!K@," 2016.

[3] V. Levenshtein, "Binary codes capable of correcting deletions, insertions, and reversals," Sov. Phys. Dokl., 1966.

[4] J. R. S. Sagala Guntur, "Deteksi Tingkat Kemiripan Data Siswa Peserta Ujian Berbasis Komputer Pada Bimbingan Belajar Expert Dengan Menggunakan Metode Levenshtein Distance," Algoritm. J. Ilmu Komput. Dan Inform., 2017. 